\title{
Effectiveness of digestive endoscopy and surgery in the treatment of necrotizing pancreatitis: a meta-analysis and systematic review
}

\author{
Peng Tang ${ }^{1 \#}$, Qinqing Zha ${ }^{2 \#}$, Lihua Zhou ${ }^{2}$, Qiulian Yang $^{3}$, Mingfeng $\mathrm{He}^{2}$, Shaomin Zhu ${ }^{4}$, Yan Liu ${ }^{5}$ \\ ${ }^{1}$ Department of Gastroenterology, Eastern Hospital, Sichuan Academy of Medical Sciences \& Sichuan Provincial People's Hospital, Chengdu, China; \\ ${ }^{2}$ Digestive Endoscopy Center, Sichuan Academy of Medical Sciences \& Sichuan Provincial People's Hospital, Chengdu, China; ${ }^{3}$ Second Internal \\ Medicine, Yilong County People's Hospital, Nanchong, China; ${ }^{4}$ Department of Anesthesiology, Eastern Hospital, Sichuan Academy of Medical \\ Sciences \& Sichuan Provincial People's Hospital, Chengdu, China; ${ }^{5}$ Department of Geriatric Internal Medicine, Sichuan Academy of Medical \\ Sciences \& Sichuan Provincial People's Hospital, Chengdu, China \\ Contributions: (I) Conception and design: P Tang, Q Zha, S Zhu, Y Liu; (II) Administrative support: L Zhou, M He; (III) Provision of study materials \\ or patients: P Tang, Q Zha, L Zhou, Q Yang, M He, Y Liu; (IV) Collection and assembly of data: All authors; (V) Data analysis and interpretation: P \\ Tang, Q Yang, S Zhu, Y Liu; (VI) Manuscript writing: All authors; (VII) Final approval of manuscript: All authors. \\ \#These authors contributed equally to this work. \\ Correspondence to: Yan Liu. Department of Geriatric Internal Medicine, Sichuan Academy of Medical Sciences \& Sichuan Provincial People's \\ Hospital, West Section 2, First Ring Road, Qingyang District, Chengdu, China. Email: xiran22831662@163.com; Shaomin Zhu. Department of \\ Anesthesiology, Eastern Hospital, Sichuan Academy of Medical Sciences \& Sichuan Provincial People's Hospital, No. 585, North Honghe Road, \\ Damian Town, Longquanyi District, Chengdu, China. Email: zhushaomin1983@163.com.
}

Background: Digestive endoscopy and surgery are the primary invasive methods for the clinical treatment of necrotizing pancreatitis. However, there are relatively few studies evaluating the effectiveness and safety of these two methods.

Methods: Randomized controlled trials (RCTs) on endoscopic and surgical treatment of necrotizing pancreatitis published from January 2000 to December 2020 were searched in the PubMed, Medline, Embase, China Biology Medicine Disc (CBM), and WanFang databases. The Cochrane System Review Manual was adopted to evaluate the quality of the included literature, and Review Manager 5.3 was used for data analysis.

Results: Ten articles were included in this meta-analysis, involving a total of 401 patients, including 188 in the endoscopy group and 213 in the surgery group. Meta-analysis results revealed that the clinical remission rate $(\mathrm{CRR})$ [odds ratio $(\mathrm{OR})=1.30,95 \%$ confidence interval $(\mathrm{CI}): 0.58-2.92, \mathrm{P}=0.52$ ], new organ failure rate $(\mathrm{OFR})(\mathrm{OR}=0.53,95 \% \mathrm{CI}: 0.26-1.09, \mathrm{P}=0.08)$, abdominal bleeding rate $(\mathrm{ABR})(\mathrm{OR}=0.62,95 \% \mathrm{CI}$ : $0.33-1.15, \mathrm{P}=0.13$ ), and intensive care unit (ICU) stay time (IST) [mean deviation (MD) $=-7.33,95 \% \mathrm{CI}$ : -16.76 to $2.11, \mathrm{P}=0.13$ ] were not significantly different between the endoscopy and surgery groups. In the endoscopy group, the mortality rate $(\mathrm{OR}=0.56,95 \% \mathrm{CI}$ : $0.31-1.02, \mathrm{P}=0.05)$, intestinal fistula rate (IFR) or gastrointestinal perforation rate $(\mathrm{GPR})(\mathrm{OR}=0.50,95 \% \mathrm{CI}: 0.26-0.99, \mathrm{P}=0.05)$, and pancreatic fistula rate (PFR) (OR =0.09, 95\% CI: 0.04-0.23, $\mathrm{P}<0.00001)$ were markedly lower compared to the surgery group.

Discussion: There was no obvious difference in the clinical efficacy of endoscopic and surgical treatment of necrotizing pancreatitis. However, endoscopy can greatly reduce the incidence of postoperative death and major complications in patients.

Keywords: Digestive endoscopy; surgery; necrotizing pancreatitis; incidence of postoperative complications; meta-analysis

Submitted Jul 21, 2021. Accepted for publication Sep 09, 2021.

doi: $10.21037 / \mathrm{gs}-21-516$

View this article at: https://dx.doi.org/10.21037/gs-21-516

(c) Gland Surgery. All rights reserved. 


\section{Introduction}

Acute pancreatitis is a clinically critical illness (1). According to the degree of disease, it can be divided into mild, moderate, and severe acute pancreatitis, and can be classified into interstitial edema pancreatitis and necrotizing pancreatitis according to the imaging characteristics (2). Acute necrotizing pancreatitis (ANP) accounts for approximately $20 \%$ of acute pancreatitis cases (3). In clinical practice, approximately $30 \%$ of patients with necrotizing pancreatitis develop infectious pancreatic necrosis, thus invasive intervention is required (4). Drug treatment of necrotizing pancreatitis can be divided into the following: one is to prevent shock and improve microcirculation, that is, to actively supplement fluid, electrolytes and calories to maintain the stability of circulation and balance of water and electrolyte. The second is to take the method of inhibiting pancreatic secretion, and for severe acute pancreatitis, use somatostatin or the long-acting analog octreotide. When the necrotic tissue has secondary infection, that is, infected pancreatic necrosis (IPN), it needs to use digestive endoscopy for intervention. The traditional invasive intervention treatment method is the application of open surgery to remove necrotic tissue. In recent years, minimally-invasive surgical treatment techniques, percutaneous catheter drainage (PCD), laparoscopic cystogastrostomy (LC), and video-assisted retroperitoneal debridement (VARD) have become the first choice for surgery (5-7). With the gradual development of endoscopic technology, endoscopic transgastric necrosectomy $(\mathrm{ETN})$ and endoscopic transgastric drainage (ETD) technologies have also been promoted and applied clinically, realizing excellent therapeutic effects $(8,9)$. In the past 10 years, in the invasive treatment of necrotizing pancreatitis, the traditional open debridement has been gradually replaced by minimally invasive surgery. Minimally invasive surgery can significantly reduce mortality and postoperative complications. Therefore, minimally invasive digestive endoscopic treatment is a common method for the treatment of necrotizing pancreatitis.

Surgery and digestive endoscopy treatments can both utilize the ascending steps method. Essentially, this involves further endoscopic debridement being applied when a patient's surgery proves ineffective (10). However, there are relatively few studies on the effectiveness and safety of digestive endoscopy and surgery in the treatment of necrotizing pancreatitis, with most of these being retrospective analyses. In order to provide more effective evidence-based medical evidence for the clinical treatment of necrotizing pancreatitis, clinical studies on endoscopic and surgical treatment of necrotizing pancreatitis were searched for inclusion in this meta-analysis, in order to compare the effectiveness and safety of these two methods. Recently, there are not many studies exploring the advantages and disadvantages of endoscopic treatment of necrotizing pancreatitis. Most of them are retrospective cohort studies, and there are confounding factors that lead to low reliability of the results. So far, there are 3 randomized controlled trial (RCT) endoscopic treatments for the efficacy and safety of necrotizing pancreatitis, but the number of cases in a single study is limited, the endoscopic or surgical treatment methods used in each study are not the same, and the results of the study are also different. In addition, RCT only includes IPN patients, and do not consider symptomatic aseptic necrosis, and the scope of application of the conclusion is limited. Therefore, this research combined all the published clinical research results and included a high-quality cohort study to systematically evaluate the pros and cons of endoscopic and surgical treatment of necrotizing pancreatitis, thus providing evidence for guiding the choice of invasive treatment for necrotizing pancreatitis.

We present the following article in accordance with the PRISMA reporting checklist (available at https://dx.doi. org/10.21037/gs-21-516).

\section{Methods}

\section{Inclusion and exclusion criteria}

The inclusion criteria were defined as follows: (I) studies whose subjects were diagnosed with necrotizing pancreatitis; (II) articles involving intervention treatment measures for patients, including digestive endoscopy and surgery treatment groups [digestive endoscopy can be divided into: ETD and ETN, and surgical treatment can be divided into PCD, LC, VARD, and open necrosectomy $(\mathrm{ON})$ ]; (III) studies involving $\geq 3$ patients; (IV) no limitation on the research type; and (V) no limitation on the language.

The exclusion criteria were defined as follows: (I) repeatedly published articles; (II) studies with unclear patient diagnosis criteria; (III) articles without clear research analysis methods; (IV) articles without clear main outcome variables; (V) studies whose original research data could not be obtained; and (VI) studies involving patients who had previously received other invasive surgery. 


\section{Retrieval of related articles}

Articles published between January 2000 and December 2020 in the PubMed, Medline, Embase, China Biology Medicine Disc (CBM), and WanFang databases were retrieved. The retrieval strategy and principles were as follows: (I) the subject terms and free words included "necrotizing pancreatitis", "endoscopy", and "surgery"; (II) the above phrases were optimally combined and searched, so as to obtain the most relevant documents; (III) the search term could be found in the title, keywords, or abstract; and (IV) part of the references of the articles could be traced back, so that the full text could be manually searched and included.

\section{Article screening and data extraction}

Two experts were invited to read the titles and abstracts of the articles to screen and extract the required data. Any disagreements between the experts were resolved through discussion, and arbitration by a third expert (if needed).

The extracted data included the following: first author, publication year, research method, sample size, surgical treatment method, complication rate, mortality rate, clinical sustained-release rate, hospital stay, and number of operations. The researcher was required to verify the data for subsequent systematic analysis.

\section{Risk of bias and quality assessment of articles}

The Cochrane randomized trial risk assessment tool was applied to evaluate the quality of the included articles. The evaluation included the following six items: (I) the random sequence generation method; (II) whether there was bias in the allocation process; (III) whether the blind research was adopted; (IV) whether the results data was complete; (V) whether there was selective reporting of the research results; and (VI) other deviations.

\section{Sensitivity analysis}

Sensitivity analysis was used to evaluate whether the results of meta-analysis were stable and reliable. Some controversial and low-quality literatures were excluded. Different statistical methods/effect models were undertaken to analyze the same set of data, and observe the changes in the results of meta-analysis. If the sensitivity analysis did not substantially change the results, it indicated that the results were reliable; on the contrary, it indicated that research should be very cautious in interpreting the results and drawing conclusions.

\section{Statistical analysis}

Review Manager 5.3 software (Copenhagen: The Nordic Cochrane Center, The Cochrane Collaboration, 2014) was adopted for statistical analysis. Binary variables included the odds ratio (OR) or relative risk (RR), and the $95 \%$ confidence interval (CI) was used for each effect size. $\mathrm{P}<0.05$ was considered to indicate a statistically significant difference. The $\mathrm{I}^{2}$ statistic was utilized to quantitatively evaluate the heterogeneity of the articles. If $\mathrm{I}^{2}<50 \%$, there was no obvious heterogeneity, and the fixed effects model (FEM) could be used for analysis. However, if $\mathrm{I}^{2}>50 \%$, the articles showed obvious heterogeneity, and the random effects model (REM) was adopted for analysis. A funnel chart was drawn to analyze the publication bias of the included articles. In addition, the symmetry of the funnel chart and the concentration of the sample towards the midline were evaluated.

\section{Results}

\section{Article retrieval and characteristics analysis}

Based on the Cochrane system search strategy, a total of 1,618 articles were retrieved. After the titles, abstracts, and full texts were read carefully, repeatedly published articles and those failing to meet the inclusion criteria were excluded. Finally, 10 articles, involving a total of 401 patients, were included in this study (11-20), including 188 patients in the endoscopy group and 213 patients in the surgery group. The article retrieval process is shown in Figure 1, and the basic information of the included research articles is shown in Table 1. For the included studies, the treatment effects of the two methods were compared according to the main methods used, and the methodological quality of each research in the intervention results was medium or above, at the same level of literature quality, and there was no methodological heterogeneity. Therefore, this systematic review did not conduct sensitivity analysis.

\section{Quality assessment of included articles}

The bias risk assessment tool recommended by the Cochrane System Review Manual was applied to evaluate the quality of the 10 articles included in this study, and 
Identification of studies via databases and registers

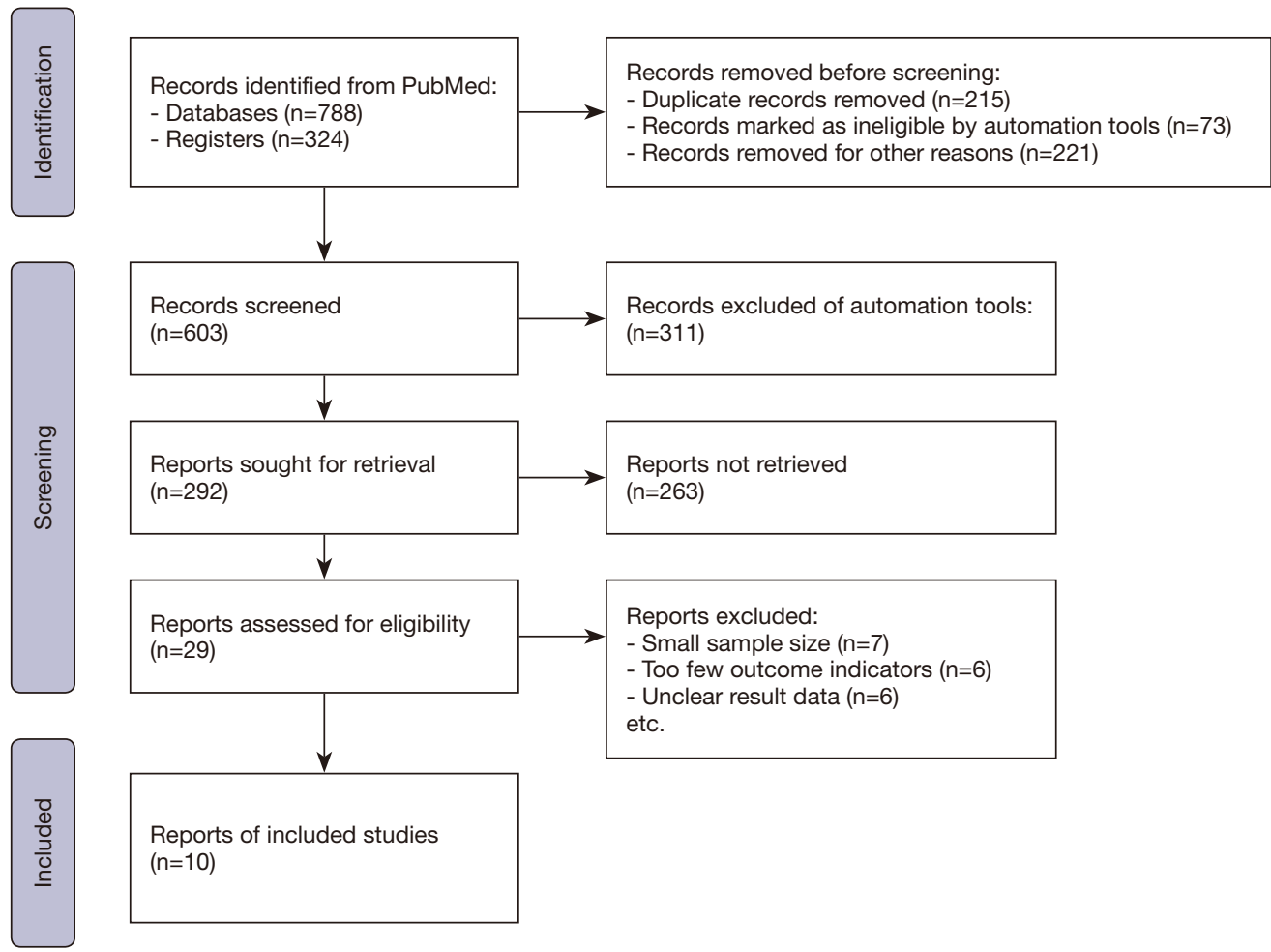

Figure 1 Article retrieval process.

Table 1 The basic characteristics of the included articles

\begin{tabular}{|c|c|c|c|c|}
\hline First author & Publication year & Number of cases $(E / S)$ & Endoscopy group & Surgery group \\
\hline Bang & 2019 & $34 / 32$ & ETD + ETN & LC + VARD \\
\hline Bausch & 2012 & $18 / 44$ & ETN & ON + VARD \\
\hline $\mathrm{He}$ & 2017 & $11 / 13$ & ETD + ETN & $\mathrm{PCD}+\mathrm{ON}$ \\
\hline Kumar & 2014 & $12 / 12$ & ETN & $\mathrm{LC}+\mathrm{ON}$ \\
\hline Mui & 2005 & $9 / 4$ & ETD + ETN & ON \\
\hline Tan & 2014 & $11 / 21$ & ETD + ETN & ON \\
\hline van Brunschot & 2018 & $51 / 47$ & ETN & $P C D+V A R D$ \\
\hline
\end{tabular}

E/S, endoscopy group/surgery group; ETN, endoscopic transgastric necrosectomy; ETD, endoscopic transgastric drainage; ON, open necrosectomy; VARD, video-assisted retroperitoneal debridement; LC, laparoscopic cystogastrostomy; PCD, percutaneous catheter drainage. 


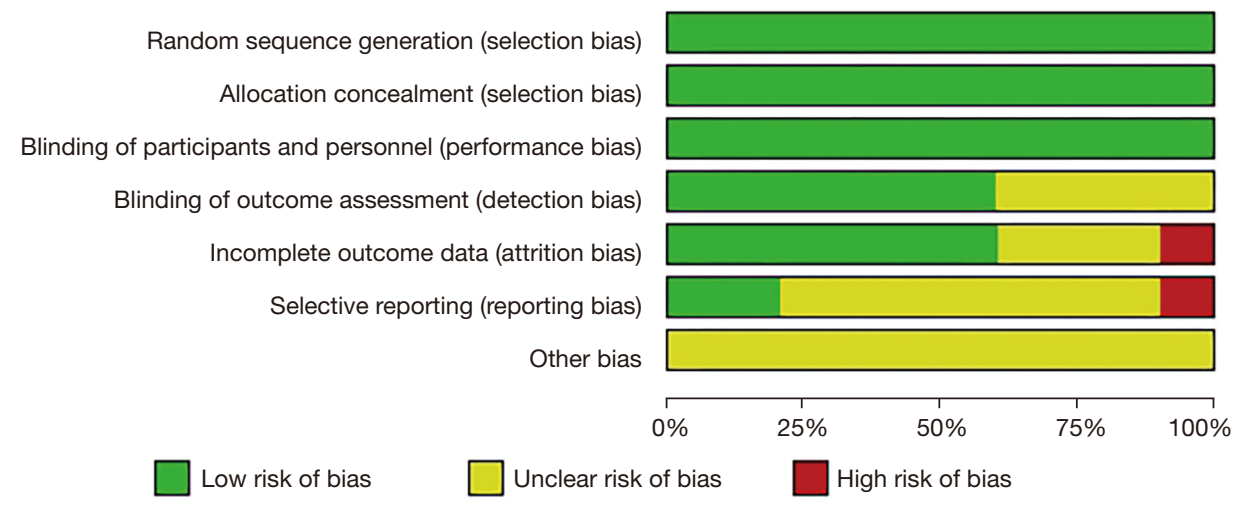

Figure 2 Risk of bias assessment of the included articles.

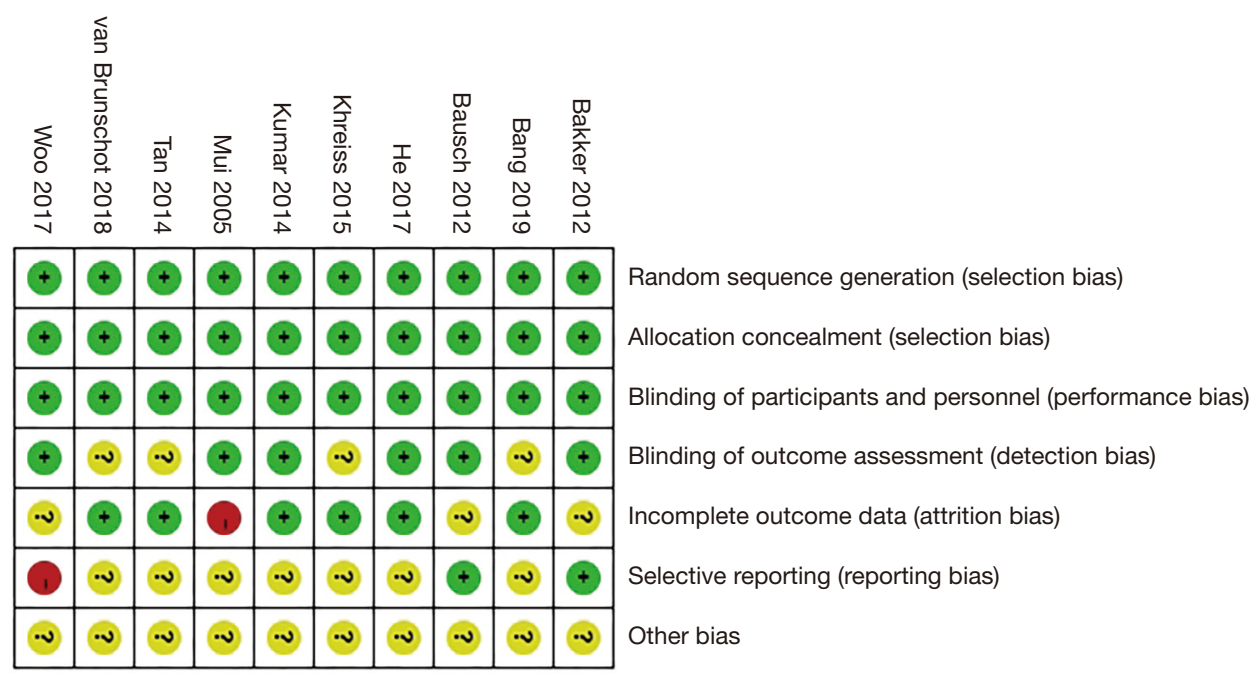

Figure 3 Risk bias evaluation results of included articles.

the results are shown in Figures 2,3. The figures revealed that there was no random sequence generation (selection bias), allocation concealment (selection bias), and blinding of outcome assessment (detection bias) in six articles. Mui et al. (17) exhibited a high risk due to incomplete outcome data (attrition bias), while Woo et al. (20) showed a high risk due to selective reporting (reporting bias). The other studies were either low risk or unknown risk.

\section{Meta-analysis results}

\section{Clinical remission rate (CRR)}

Differences in the CRR of patients in the endoscopy and surgery groups were compared and analyzed, (as shown in Figure 4). Based on the $\mathrm{I}^{2}$ statistic, it was observed that there was no obvious heterogeneity in the CRR of patients in the endoscopy and surgery groups $\left(\mathrm{I}^{2}=0 \%, \mathrm{P}=0.99\right)$, so the FEM was used for statistical analysis thereafter. The results demonstrated that the meta-analysis effect value of the CRR after treatment in the endoscopy and surgery groups patients was OR (95\% CI): 1.30 (0.58-2.92), and the statistical test structure was $\mathrm{Z}=0.65(\mathrm{P}=0.52)$. In summary, the difference in CRR between endoscopy and surgery group patients after treatment was not statistically significant $(\mathrm{P}>0.05)$.

\section{Mortality rate}

Differences in the mortality rate of patients in the endoscopy and surgery groups after treatment was analyzed and compared (as shown in Figure 5). Based on the $\mathrm{I}^{2}$ statistic, it was observed that there was no obvious 


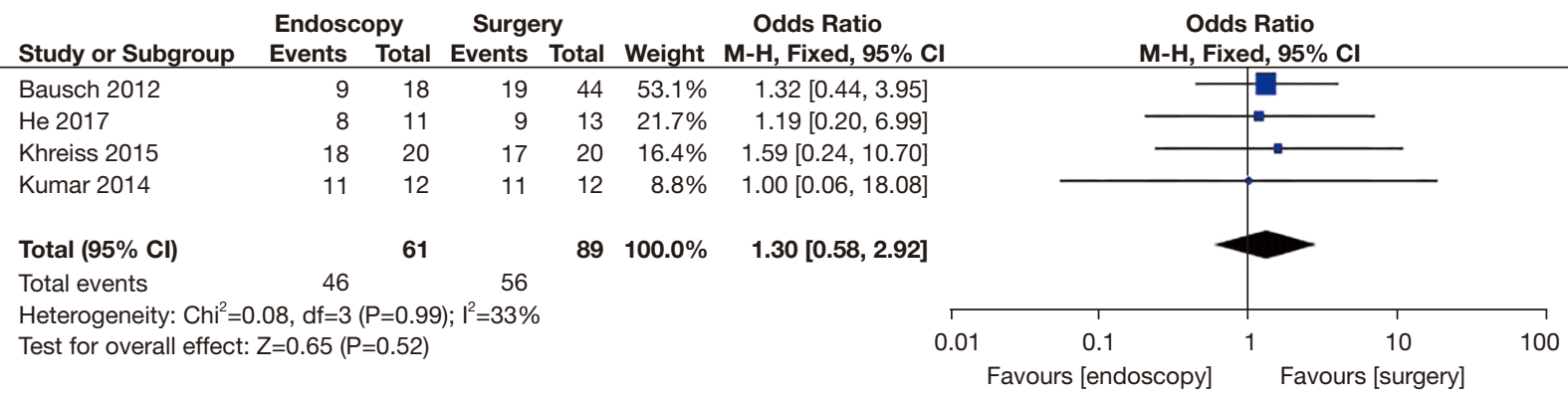

Figure 4 Forest map for CRR comparison of patients after treatment. CRR, clinical remission rate; CI, confidence interval.

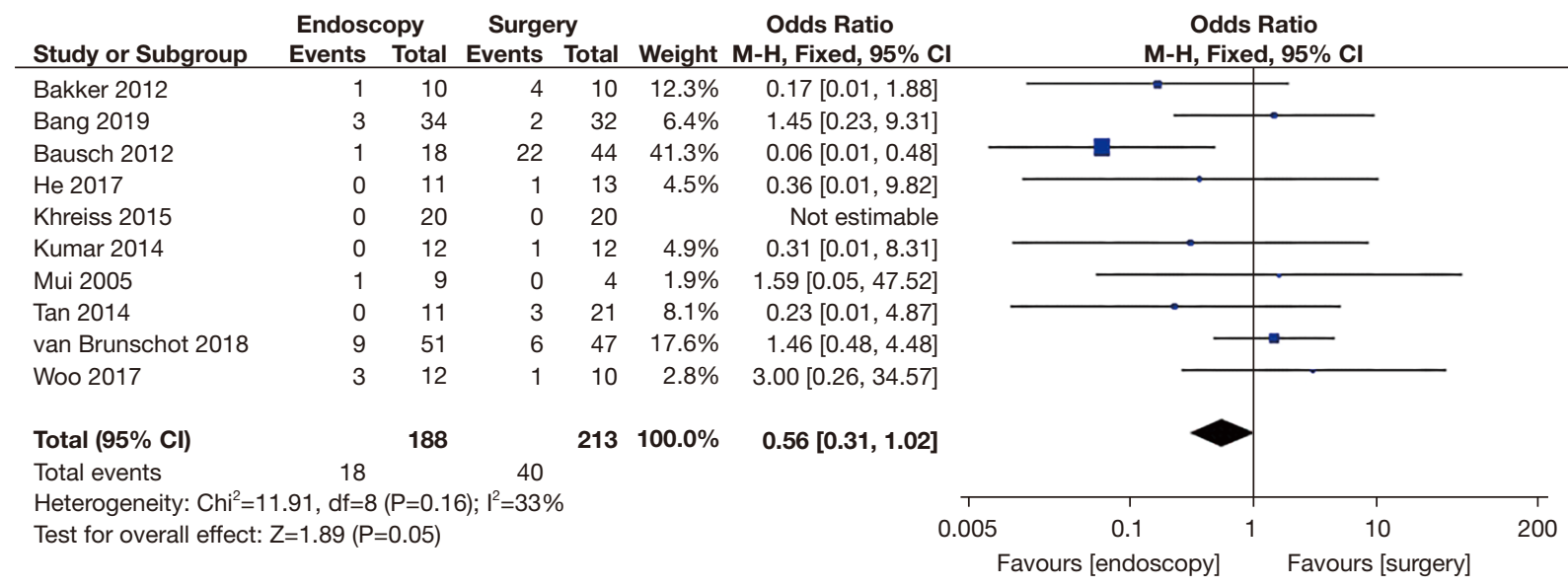

Figure 5 Forest map for mortality rate comparison of patients after treatment. CI, confidence interval.

heterogeneity in the mortality rate of patients in the two groups after treatment $\left(\mathrm{I}^{2}=33 \%, \mathrm{P}=0.16\right)$, so the $\mathrm{FEM}$ was used for statistical analysis thereafter. The results revealed that the meta-analysis effect value of the mortality rate of patients in both groups after treatment was OR $(95 \%$ CI): 0.56 (0.31-1.02), and the statistical test structure was $\mathrm{Z}=1.89$ ( $\mathrm{P}=0.05)$. In summary, the mortality rate of patients in the endoscopy group after treatment was clearly lower than that in the surgery group, and the difference was statistically significant $(\mathrm{P}<0.05)$.

\section{Postoperative organ failure rate (OFR)}

Differences in the postoperative OFR between patients in the endoscopy and surgery groups were compared and analyzed (as shown in Figure 6). Based on the $\mathrm{I}^{2}$ statistic, it was observed that there was no significant heterogeneity $\left(\mathrm{I}^{2}=0 \%, \mathrm{P}=0.53\right)$ in the postoperative OFR for patients in the endoscopy and surgery groups, so the FEM was used for statistical analysis thereafter. The results suggested that the meta-analysis effect value of postoperative OFR was OR (95\% CI): $0.53(0.26-1.09)$, and the statistical test structure was $\mathrm{Z}=1.74(\mathrm{P}=0.08)$. In summary, the difference in postoperative OFR of patients in the endoscopy and surgery groups was not statistically significant $(\mathrm{P}>0.05)$.

\section{Postoperative abdominal bleeding rate (ABR)}

Differences in the postoperative ABR between patients in the endoscopy and surgery groups were compared and analyzed (as shown in Figure 7). Based on the $\mathrm{I}^{2}$ statistic, it was observed that there was no significant heterogeneity $\left(\mathrm{I}^{2}=0 \%, \mathrm{P}=0.90\right)$ in the postoperative ABR of patients in the endoscopy and surgery groups, so the FEM was used for statistical analysis thereafter. The results suggested that the meta-analysis effect value of postoperative $\mathrm{ABR}$ was $\mathrm{OR}$ (95\% CI): 0.62 (0.33-1.15), and the statistical test structure was $\mathrm{Z}=1.51(\mathrm{P}=0.13)$. In summary, the difference in postoperative $\mathrm{ABR}$ of patients in the endoscopy and surgery groups was not statistically significant $(\mathrm{P}>0.05)$. 


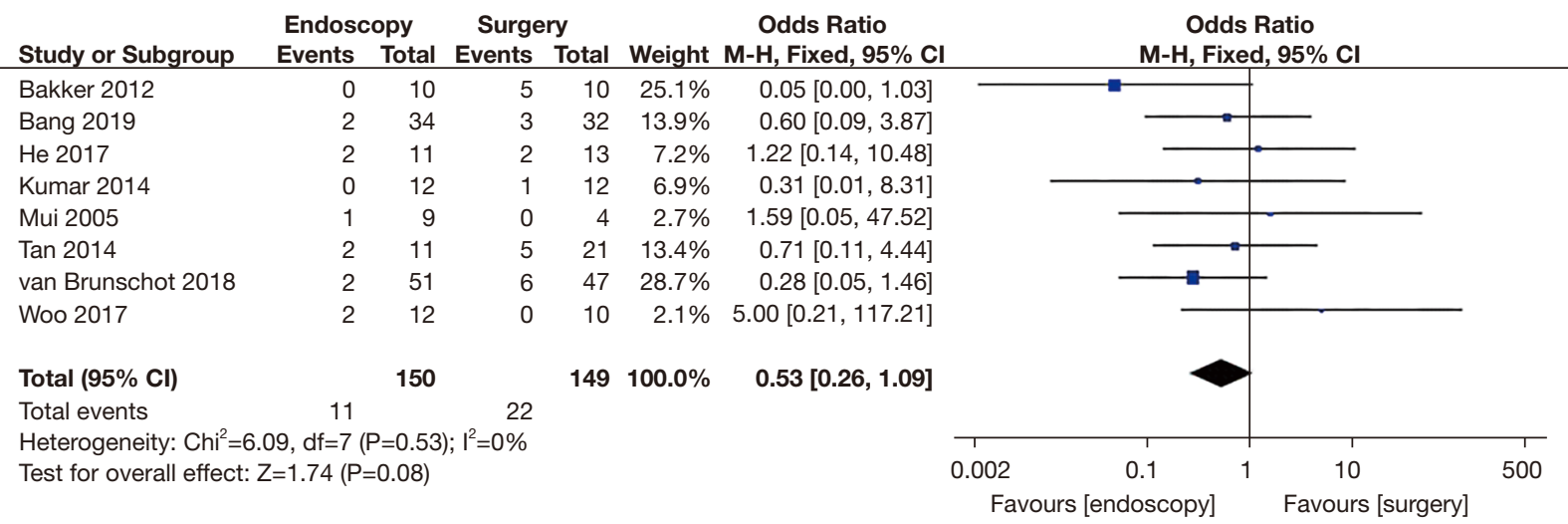

Figure 6 Forest map for postoperative OFR comparison of patients after treatment. OFR, organ failure rate; CI, confidence interval.

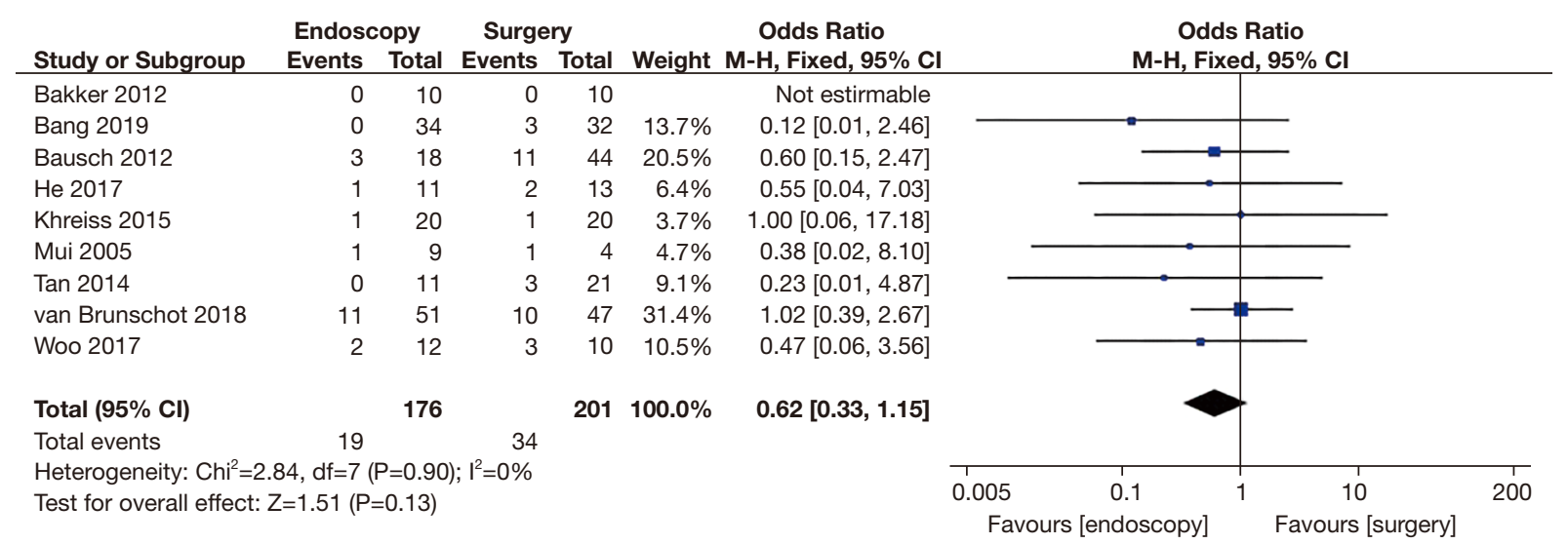

Figure 7 Forest map for postoperative ABR comparison of patients after treatment. ABR, abdominal bleeding rate; CI, confidence interval.

\section{Postoperative intestinal fistula rate (IFR) or gastrointestinal perforation rate (GPR)}

Differences in the postoperative IFR or GPR between patients in the endoscopy and surgery groups were compared and analyzed (as shown in Figure 8). Based on the $\mathrm{I}^{2}$ statistic, it was observed that there was no significant heterogeneity $\left(\mathrm{I}^{2}=0 \%, \mathrm{P}=0.43\right)$ in the postoperative IFR or GPR of patients in the endoscopy and surgery groups, so the FEM was used for statistical analysis thereafter. The results suggested that the meta-analysis effect value of postoperative IFR or GPR was OR (95\% CI): 0.50 (0.26$0.99)$, and the statistical test structure was $\mathrm{Z}=1.99(\mathrm{P}=0.05)$. In summary, the differences in the postoperative IFR or GPR of patients in the endoscopy and surgery groups were not statistically significant $(\mathrm{P}>0.05)$.

\section{Postoperative pancreatic fistula rate (PFR)}

Differences in the postoperative PFR between patients in the endoscopy and surgery groups were compared and analyzed (as shown in Figure 9). Based on the $\mathrm{I}^{2}$ statistic, it was observed that there was no significant heterogeneity $\left(\mathrm{I}^{2}=0 \%, \mathrm{P}=0.99\right)$ in the postoperative PFR of patients in the endoscopy and surgery groups, so the FEM was used for statistical analysis thereafter. The results suggested that the meta-analysis effect value of postoperative PFR was OR (95\% CI): 0.09 (0.04-0.23), and the statistical test structure was $Z=5.16(\mathrm{P}<0.00001)$. In summary, the difference in postoperative $\mathrm{PFR}$ of patients in the endoscopy and surgery groups was statistically significant $(\mathrm{P}<0.05)$.

Postoperative intensive care unit (ICU) stay time (IST) Differences in the postoperative IST between patients in the endoscopy and surgery groups were compared and analyzed (as shown in Figure 10). Based on the $\mathrm{I}^{2}$ statistic, it was observed that there was significant heterogeneity $\left(\mathrm{I}^{2}=78 \%, \mathrm{P}=0.010\right)$ in the postoperative IST of patients in 


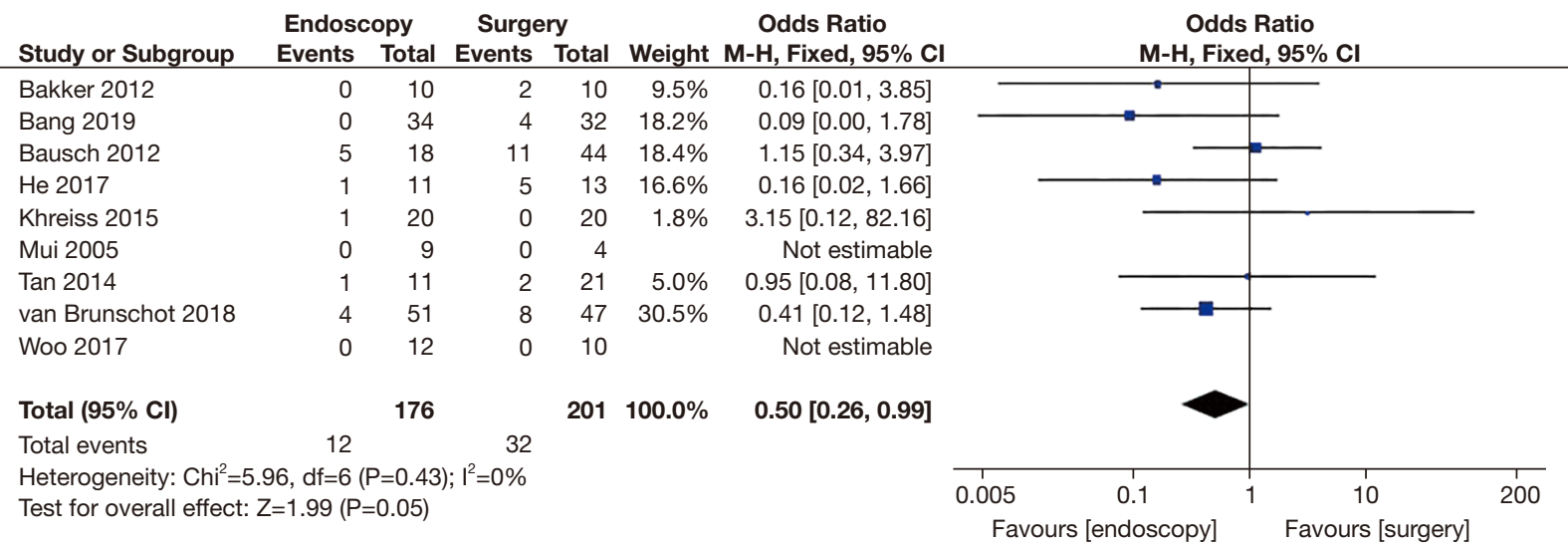

Figure 8 Forest map for postoperative IFR or GPR comparison of patients after treatment. IFR, intestinal fistula rate; GPR, gastrointestinal perforation rate; CI, confidence interval.

\begin{tabular}{|c|c|c|c|c|c|c|c|c|c|}
\hline Study or Subgroup & \multicolumn{2}{|c|}{ Endoscopy } & \multicolumn{2}{|c|}{ Surgery } & \multirow{2}{*}{$\begin{array}{r}\text { Weight } \\
14.0 \%\end{array}$} & $\begin{array}{c}\text { Odds Ratio } \\
\text { M-H, Fixed, } 95 \% \text { CI }\end{array}$ & \multicolumn{3}{|c|}{$\begin{array}{c}\text { Odds Ratio } \\
\text { M-H, Fixed, 95\% Cl }\end{array}$} \\
\hline Bakker 2012 & 1 & 10 & 7 & 10 & & $0.05[0.00,0.56]$ & & & \\
\hline Bang 2019 & 0 & 34 & 8 & 32 & $19.2 \%$ & $0.04[0.00,0.76]$ & & & \\
\hline Bausch 2012 & 0 & 18 & 7 & 44 & $9.7 \%$ & $0.14[0.01,2.50]$ & & & \\
\hline He 2017 & 0 & 11 & 1 & 13 & $3.0 \%$ & $0.36[0.01,9.82]$ & & & \\
\hline Mui 2005 & 0 & 9 & 1 & 4 & $4.2 \%$ & $0.12[0.00,3.78]$ & & & \\
\hline Tan 2014 & 0 & 11 & 8 & 21 & $12.8 \%$ & $0.07[0.00,1.33]$ & & & \\
\hline van Brunschot 2018 & 2 & 51 & 13 & 47 & $29.0 \%$ & $0.11[0.02,0.50]$ & & & \\
\hline Woo 2017 & 0 & 12 & 3 & 10 & $8.1 \%$ & $0.09[0.00,1.90]$ & & & \\
\hline Total $(95 \% \mathrm{Cl})$ & & 156 & & 181 & $100.0 \%$ & $0.09[0.04,0.23]$ & & & \\
\hline Total events & 3 & & 48 & & & & & & \\
\hline \multicolumn{7}{|c|}{ Heterogeneity: $C \mathrm{Ci}^{2}=1.39, \mathrm{df}=7(\mathrm{P}=0.99) ; \mathrm{I}^{2}=0 \%$} & & & \\
\hline \multicolumn{7}{|c|}{ Test for overall effect: $Z=5.16(P<0.00001)$} & $\begin{array}{ll}0.01 & 0.1 \\
& \text { Favours [endoscopy] }\end{array}$ & Favours & $\begin{array}{l}10 \\
\text { [surgery] }\end{array}$ \\
\hline
\end{tabular}

Figure 9 Forest map for postoperative PFR comparison of patients after treatment. PFR, pancreatic fistula rate; CI, confidence interval.

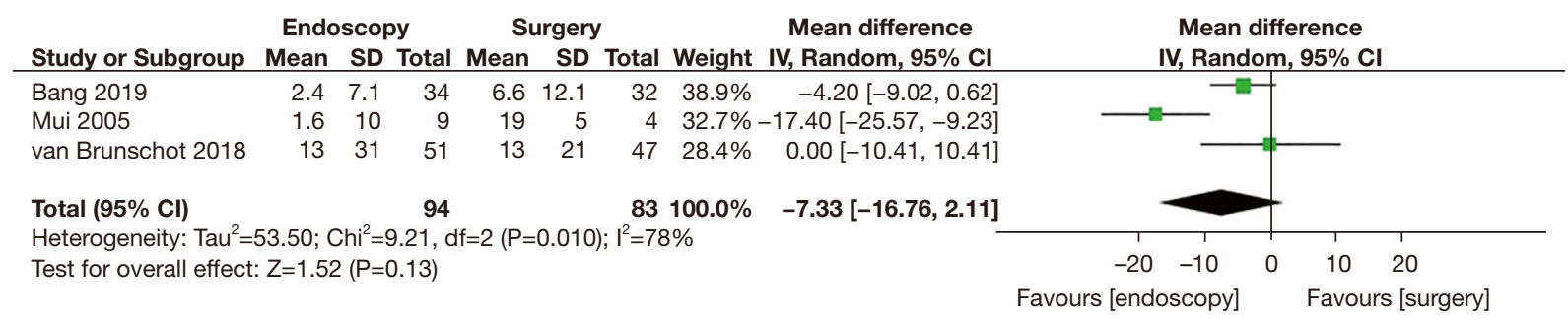

Figure 10 Forest map for postoperative IST comparison of patients after treatment. IST, ICU stay time; ICU, intensive care unit; CI, confidence interval.

the endoscopy group and surgery group, so the REM was used for statistical analysis thereafter. The results suggested that the meta-analysis effect value of postoperative IST was OR (95\% CI): -7.33 (-16.76 to 2.11$)$, and the statistical test structure was $\mathrm{Z}=1.52(\mathrm{P}=0.13)$. In summary, the difference in postoperative IST of patients in the endoscopy and surgery groups was not statistically significant $(\mathrm{P}>0.05)$.

Publication bias analysis

Figures 11-13 illustrate the publication bias of indicators 


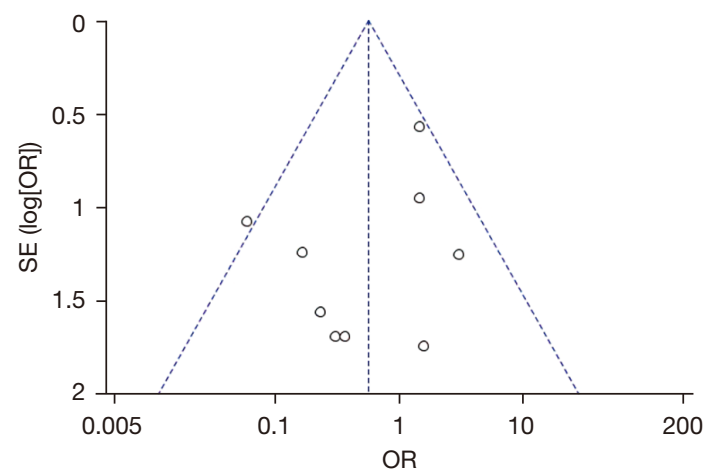

Figure 11 Funnel chart for the postoperative mortality rate of patients. SE, standard error; OR, odds ratio.

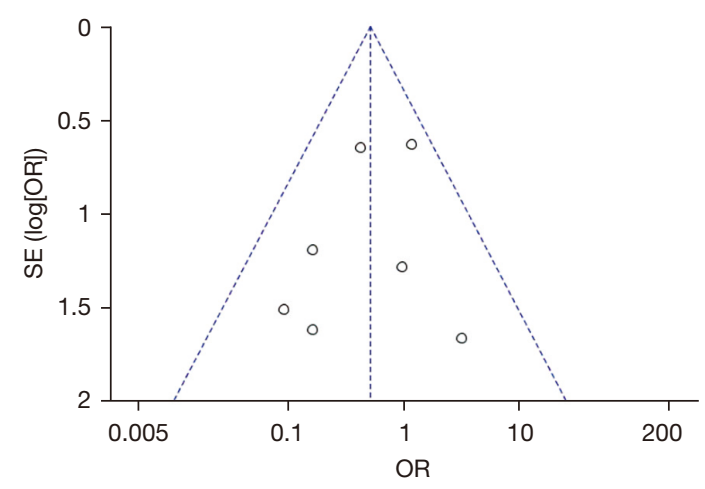

Figure 12 Funnel chart for the postoperative IFR or GPR of patients. IFR, intestinal fistula rate; GPR, gastrointestinal perforation rate; SE, standard error; OR, odds ratio.

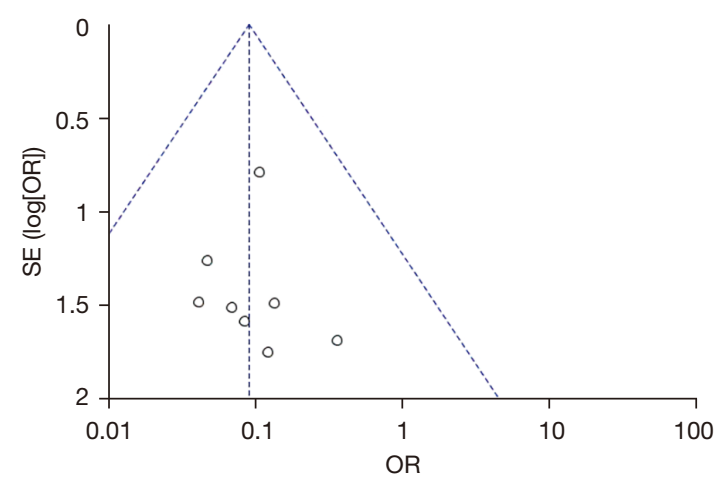

Figure 13 Funnel chart for the postoperative PFR of patients. PFR, pancreatic fistula rate; SE, standard error; OR, odds ratio. with statistically obvious differences for patients in the endoscopy and surgery groups. The funnel charts of mortality rate and IFR or GPR were more symmetrical, and the data was also more concentrated. The funnel chart for PFR was relatively offset and not symmetrical enough; however, all of the included articles fell into the chart and were close to the midline. This suggested that the publication bias of the included articles was low and met the requirements.

\section{Discussion}

Infectious necrosis and symptomatic aseptic necrosis in acute pancreatitis are the main complications after invasive treatment (21). Necrotizing pancreatitis accounts for approximately $20 \%$ of acute pancreatitis cases, some of which are moderate acute pancreatitis or accompanied by transient organ failure, and the mortality rate is less than $5 \%$. The remaining cases are accompanied by persistent organ failure, which can develop into severe acute pancreatitis, exhibiting accumulation of acute necrotic substances in the early stage, and the mortality rate can reach $10 \%$ (22). In recent years, a large number of studies have demonstrated that in the invasive treatment of necrotizing pancreatitis, minimally invasive surgery has gradually replaced traditional open debridement and shown lower postoperative complications and mortality $(23,24)$. With the rapid development of endoscopic technology, endoscopic drainage, and debridement treatment have also been widely used in clinical practice, achieving excellent therapeutic effects (25). Compared with surgery, endoscopic treatment can significantly reduce the incidence of three complications in the composite outcome variable, including new organ failure, intestinal cutaneous fistula or perforation of the digestive tract, and pancreatic fistula. It shows that the safety of endoscopic treatment is higher than that of surgical treatment.

However, there are relatively few studies on the effectiveness and safety of endoscopic and surgery debridement in the treatment of necrotizing pancreatitis. This may be due to the relatively small clinical proportion of necrotizing acute pancreatitis (only approximately $20 \%$ ), so the number of cases requiring debridement treatment is relatively small (approximately $4 \%$ ) (26). In 
addition, the risk of open surgery is high, so there are few clinical studies on the use of surgical open surgery alone (27). Endoscopic treatment is a newly-developed method, and the organizations that can utilize this technology for treatment are currently very limited, thus the clinical application data for this technology are still in the emerging stage (28).

Most of the current studies on the endoscopic and surgical treatment of necrotizing pancreatitis are retrospective analyses. Therefore, recent clinical studies on endoscopic and surgical treatment of necrotizing pancreatitis were retrieved in this study for meta-analysis and systematic review. The results showed that the postoperative mortality, intestinal cutaneous fistula, gastrointestinal perforation, and pancreatic fistula were significantly lower in patients who underwent endoscopic debridement treatment. Also, there was no significant difference in the CRR of patients after endoscopic or surgical treatment. These results suggested that endoscopic debridement can greatly reduce the incidence of postoperative complications in patients with necrotizing pancreatitis while ensuring adequate therapeutic effect.

\section{Conclusions}

In this study, a total of 10 related articles were included for meta-analysis of the effects of endoscopic and surgical debridement of necrotizing pancreatitis, in order to systematically evaluate the clinical effectiveness and safety of these treatments. The results revealed that endoscopic treatment can effectively reduce the mortality rate of postoperative patients, and can also reduce the probability of intestinal cutaneous fistula or gastrointestinal perforation and pancreatic fistula after surgery. At present, the application of endoscopic surgery has been relatively mature. During the operation, the endoscope can be used to locate the necrotic site, which can significantly improve the treatment efficiency and safety.

However, there were some limitations in this study that should be noted. Firstly, only existing articles were included in the systematic evaluation. The patients included in the articles did not receive one treatment method only. Therefore, a single rate analysis of the effect of endoscopic and surgical treatment of necrotizing pancreatitis is required in future research. Yet, the results of this study can provide a reference for the clinical application of endoscopic treatment of necrotizing pancreatitis.

\section{Acknowledgments}

Funding: None.

\section{Footnote}

Reporting Checklist: The authors have completed the PRISMA reporting checklist. Available at https://dx.doi. org/10.21037/gs-21-516

Conflicts of Interest: All authors have completed the ICMJE uniform disclosure form (available at https://dx.doi. org/10.21037/gs-21-516). The authors have no conflicts of interest to declare.

Etbical Statement: The authors are accountable for all aspects of the work in ensuring that questions related to the accuracy or integrity of any part of the work are appropriately investigated and resolved.

Open Access Statement: This is an Open Access article distributed in accordance with the Creative Commons Attribution-NonCommercial-NoDerivs 4.0 International License (CC BY-NC-ND 4.0), which permits the noncommercial replication and distribution of the article with the strict proviso that no changes or edits are made and the original work is properly cited (including links to both the formal publication through the relevant DOI and the license). See: https://creativecommons.org/licenses/by-nc-nd/4.0/.

\section{References}

1. Greenberg JA, Hsu J, Bawazeer M, et al. Clinical practice guideline: management of acute pancreatitis. Can J Surg 2016;59:128-40.

2. Grassedonio E, Toia P, La Grutta L, et al. Role of computed tomography and magnetic resonance imaging in local complications of acute pancreatitis. Gland Surg 2019;8:123-32.

3. Villatoro E, Mulla M, Larvin M. Antibiotic therapy for prophylaxis against infection of pancreatic necrosis in acute pancreatitis. Cochrane Database Syst Rev 2010;(5):CD002941. 
4. Italian Association for the Study of the Pancreas (AISP); Pezzilli R, Zerbi A, et al. Consensus guidelines on severe acute pancreatitis. Dig Liver Dis 2015;47:532-43.

5. Commander CW, Wilson SB, Bilaj F, et al. CT-guided percutaneous drainage catheter placement in the abdomen and pelvis: predictors of outcome and protocol for followup. J Vasc Interv Radiol 2020;31:667-73.

6. Balogun OS, Osinowo AO, Afolayan MO, et al. Laparoscopic transgastric sutured cystogastrostomy for post-traumatic pancreatic pseudocyst in a low resource setting: case report and literature review. West Afr J Med 2019;36:80-2.

7. Zhang JB, Sun B. Comparison between video-assisted retroperitoneal debridement and small incision pancreatic necrosectomy in infected pancreatic necrosis. ANZ J Surg 2020;90:2020-5.

8. Balog K, Csiszkó A, Krasnyánszky N, et al. Open transgastric necrosectomy for extended walled-off pancreas necrosis. Magy Seb 2019;72:8-12.

9. Hawel J, McFadgen H, Stewart R, et al. Interventional radiology-assisted transgastric endoscopic drainage of peripancreatic fluid collections. Can J Surg 2020;63:E254-6.

10. $\mathrm{Xu} \mathrm{Z,} \mathrm{Zheng} \mathrm{Y.} \mathrm{Percutaneous} \mathrm{endoscopic} \mathrm{debridement}$ and irrigation for thoracic infections. Rev Assoc Med Bras (1992) 2018;64:518-24.

11. Bakker OJ, van Santvoort HC, van Brunschot S, et al. Endoscopic transgastric vs surgical necrosectomy for infected necrotizing pancreatitis: a randomized trial. JAMA 2012;307:1053-61.

12. Bang JY, Arnoletti JP, Holt BA, et al. An endoscopic transluminal approach, compared with minimally invasive surgery, reduces complications and costs for patients with necrotizing pancreatitis. Gastroenterology 2019;156:1027-40.e3.

13. Bausch D, Wellner U, Kahl S, et al. Minimally invasive operations for acute necrotizing pancreatitis: comparison of minimally invasive retroperitoneal necrosectomy with endoscopic transgastric necrosectomy. Surgery 2012;152:S128-34.

14. He WH, Zhu Y, Zhu Y, et al. The outcomes of initial endoscopic transluminal drainage are superior to percutaneous drainage for patients with infected pancreatic necrosis: a prospective cohort study. Surg Endosc 2017;31:3004-13.

15. Khreiss M, Zenati M, Clifford A, et al. Cyst gastrostomy and necrosectomy for the management of sterile walled-off pancreatic necrosis: a comparison of minimally invasive surgical and endoscopic outcomes at a high-volume pancreatic center. J Gastrointest Surg 2015;19:1441-8.

16. Kumar N, Conwell DL, Thompson CC. Direct endoscopic necrosectomy versus step-up approach for walled-off pancreatic necrosis: comparison of clinical outcome and health care utilization. Pancreas 2014;43:1334-9.

17. Mui LM, Wong SK, Ng EK, et al. Combined sinus tract endoscopy and endoscopic retrograde cholangiopancreatography in management of pancreatic necrosis and abscess. Surg Endosc 2005;19:393-7.

18. Tan V, Charachon A, Lescot T, et al. Endoscopic transgastric versus surgical necrosectomy in infected pancreatic necrosis. Clin Res Hepatol Gastroenterol 2014;38:770-6.

19. van Brunschot S, van Grinsven J, van Santvoort HC, et al. Endoscopic or surgical step-up approach for infected necrotising pancreatitis: a multicentre randomised trial. Lancet 2018;391:51-8.

20. Woo S, Walklin R, Wewelwala C, et al. Interventional management of necrotizing pancreatitis: an Australian experience. ANZ J Surg 2017;87:E85-9.

21. Huber $W$, Algül H. Treatment of acute necrotizing pancreatitis. Internist (Berl) 2019;60:226-34.

22. Trikudanathan G, Wolbrink DRJ, van Santvoort $\mathrm{HC}$, et al. Current concepts in severe acute and necrotizing pancreatitis: an evidence-based approach. Gastroenterology 2019;156:1994-2007.e3.

23. El Boukili I, Boschetti G, Belkhodja H, et al. Update: role of surgery in acute necrotizing pancreatitis. J Visc Surg 2017;154:413-20.

24. Arvanitakis M, Dumonceau JM, Albert J, et al. Endoscopic management of acute necrotizing pancreatitis: European Society of Gastrointestinal Endoscopy (ESGE) evidence-based multidisciplinary guidelines. Endoscopy 2018;50:524-46.

25. Haney CM, Kowalewski KF, Schmidt MW, et al. Endoscopic versus surgical treatment for infected necrotizing pancreatitis: a systematic review and metaanalysis of randomized controlled trials. Surg Endosc 2020;34:2429-44.

26. Trikudanathan G, Tawfik P, Amateau SK, et al. Early (<4 weeks) versus standard ( $\geq 4$ weeks) endoscopically centered step-up interventions for necrotizing pancreatitis. Am J Gastroenterol 2018;113:1550-8.

27. Sakorafas GH, Sampanis D, Lappas C, et al. Necrotizing 
acute pancreatitis current status - emerging new strategies in surgical management. Infect Disord Drug Targets 2012;12:138-43.

28. Badurdeen DS, Kumbhari V. Endoscopic sleeve gastroplasty

Cite this article as: Tang P, Zha Q, Zhou L, Yang Q, He M, Zhu S, Liu Y. Effectiveness of digestive endoscopy and surgery in the treatment of necrotizing pancreatitis: a meta-analysis and systematic review. Gland Surg 2021;10(9):2754-2765. doi: $10.21037 / g s-21-516$ and its application to China. J Dig Dis 2017;18:551-5.

(English Language Editor: A. Kassem) 